\title{
Archives of
}

\section{Business Administration and Management}

Iqbal U. Arch Bus Adm Manag: ABAM-120

\section{Poverty Reduction in Ghana: Microfinance and Small Loan Centre (MASLOC) in Perspective}

\author{
Donatus Nyaaba, Francis Atintono, Sylvester Alosum Anaba"
}

Department of Statistics, Bolgatanga Polytechnic, Bolgatanga, Upper East Region, Ghana

"Corresponding author: Sylvester Alosum Anaba, Department of Statistics, Bolgatanga Polytechnic, Bolgatanga, Upper East Region, Ghana. Tel: +233-0206657666; Email: alosum@yahoo.co.uk

Citation: Nyaaba D, Atintono F, Anaba SA (2018) Poverty Reduction in Ghana: Microfinance and Small Loan Centre (MASLOC) in Perspective. Arch Bus Adm Manag: ABAM-119. DOI: 10.29011/ABAM-119. 100019

Received Date: 22 October, 2018; Accepted Date: 29 November, 2018; Published Date: 07 December, 2018

\begin{abstract}
Access to adequate and affordable credit for businesses remains one of the key challenges to local economic development in Ghana despite efforts by both government and private sector organizations to address the problem. Issues of availability of financial institutions, proximity to clients, effectiveness of service provision, adequacy of loans granted, and timeliness and cost of services provided are among factors that have been deemed critical in addressing this perennial problem. A multitude of methodologies are being used to provide financial services such as savings, credit, and insurance to relatively poor clients, yet they follow the same philosophy of group lending, forced savings, small loan amounts and short repayment periods. To give practical meaning to poverty reduction agenda, the government of Ghana launched the Microfinance and Small Loans Centre (MASLOC) in 2006. Earlier studies acknowledge the difficulties that still exist regarding access to finance, domestic resource and the support necessary for Small and Medium Enterprises (SMEs) to grow and contribute to the economy. This research is therefore aimed at investigating how MASLOC is performing its mandate of expanding micro-credit to the economically active poor in the Tamale Metropolis. A case study approach was used as the research strategy by the researcher. The researcher employed the representative single case study, primarily designed to elicit information from a cross-section of local stakeholders (especially beneficiaries and management) of MASLOC in the Tamale Metropolis. The case study approach was employed due to the fact that it provided a basis for an empirical enquiry that allows the researcher to investigate and understand the role of MASLOC in the economic life of its credit beneficiaries. It created the avenue to use multiple sources of evidence, thus improving the quality of data for the study as it allows triangulation. It was found that there are some misgivings about MASLOC scheme. These were deduced from both clients and officials of MASLOC. In many respect, the establishment of MASLOC have made some strides in the area of accessibility to micro credit and fighting the indicators of poverty. It is however, worth noting that much of the efforts have seemingly resulted into uncoordinated stakeholder action and decision making due to small amount of credit lack of skills and capacity to utilize loans and political interference. It was therefore noted that without a clear and concrete effort at diversifying the loan portfolio, encouraging micro saving among clients, monitoring the performance of beneficiaries and depoliticizing the scheme, using MASLOC to enhance accessibility of individuals, groups and households will remain a vision on paper.
\end{abstract}

Keywords: Affordable Credit; Financial Services; Low Income; Microfinance; Poverty Reduction

\section{Background of the Study}

Access to adequate and affordable credit for businesses remains one of the key challenges to local economic development in Ghana despite efforts by both government and private sector organizations to address the problem. Issues of availability of financial institutions, proximity to clients, effectiveness of service provision, adequacy of loans granted, and timeliness and cost of services provided are among factors that have been deemed critical in addressing this perennial problem. A multitude of methodologies are being used to provide financial services such as savings, credit, and insurance to relatively poor clients, yet they follow the same philosophy of group lending, forced savings, small loan amounts and short repayment periods [1]. As a strategy of poverty 


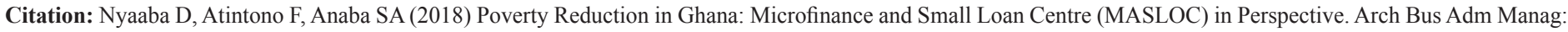
ABAM-119. DOI: 10.29011/ABAM-119. 100019

reduction, many developing countries and Non-Governmental Organizations (NGOs) in the 1970s began experimenting the giving of small loans to the under privileged in society [2]. The concept, now known as microfinance, has been adopted to expand financial resources to the people who are relatively poor. The key role of microfinance in achieving the Millennium Development Goals (MDGs) was also recognised by the United Nations hence, it declared 2005 as the year of microcredit [3]. A study by Otero $[4,5]$ suggests that microfinance creates access to productive capital for the poor, as well as strengthening them to participate in the economy and society. However, Latifee [6] articulates that in spite of the remarkable progress in the growth in number and outreach by microfinance institutions, the poorest family's access to credit is still $38 \%$ in Asia, $8.5 \%$ in Africa and the Middle East, $11.6 \%$ in Latin America and the Caribbean and 1.7\% in Europe. This confirms an earlier research by Hulme and Mosley [7], that most contemporary schemes are less effective than they might be. The realization that people who are relatively poor can borrow, use and repay loans has generated a great deal of interest in microfinance among policy makers and development practitioners as strategies for poverty reduction. Recognizing the role microfinance can play in achieving the Millennium Development Goals (MDG), the United Nations declared 2005 as the year of microcredit. This recognition and the growing interest in microfinance is not only a strategy of making financial resources available to the poor but also a significant drive for socio-economic transformation of developing economies. Therefore, microfinance has become a conduit for the provision and management of financial services and products that are targeted at the low-income clients $[1,5]$. Recognizing the crucial role of Small and Medium Scale Enterprises (SMEs) in the economic development of Ghana, government has intervened with various micro-financing schemes, such Micro-Finance and Small Loans Centre (MASLOC), Venture Capital Trust fund (VCTF) and Export Development and Investment Fund (EDIF) [8]. To give practical meaning to poverty reduction agenda, the government of Ghana launched the Microfinance and Small Loans Centre (MASLOC) in 2006. This was envisaged, among other things, to provide a one-stop shop for all activities on microfinance in the country, and to a large extent increase access to micro-credit to the economically active poor. This is expected to finance numerous small and medium scale enterprises in rural and peri-urban areas $[9,10]$. However, over $50 \%$ of microfinance demands of the existing Microfinance Institutions (MFIs) clients are not met due to limited access to on lending funds [10].

\section{Theoretical Issues}

\section{The Concept of Microfinance and Microcredit}

The term 'microcredit' was first coined in the 1970s to indicate the provision of loans to the poor to establish incomegenerating projects, while the term 'microfinance' has come to be used since the late 1990 s to indicate the so-called second revolution in credit theory and policy that are customer-centred rather than product-centred [11]. But the terms 'microcredit' and 'microfinance' tend to be used interchangeably to indicate the range of financial services offered specifically to poor, low-income households and micro-enterprises [12]. Microfinance principally encompasses microcredit, micro-savings, micro-insurance and money transfers for the poor. Microcredit, which is part of microfinance, is the practice of delivering small, collateral-free loans to usually unsalaried borrowers or members of cooperatives who otherwise cannot get access to credit [13] Micro-finance as posited by the United Nations [14] is defined as the provision of financial services and the management of small amounts of money through a range of products that are targeted at the poor people. This product includes loans, savings, insurance etc. Contributing to the conceptual explanation of micro finance, Almeyda and Branch [15] defined it as 'the provision of credit, savings, and other financial services to lower-income groups'.

\section{The Concept of Small and Medium Enterprises (SMEs)}

Story [16] argues that there is no universally accepted definition for the term small and medium scale enterprises (SMEs). Definitions that emphasise the size of firms (number of employees, turnover, profitability, etc.) when applied to a sector could lead to all firms being classified as small, while the same size criterion when applied to a different sector could lead to a different result [17]. Thus, firms differ in their levels of capitalisation, sales and employment. This has challenged any attempts at deriving a uniform definition. Despite this challenge, attempts have been made to distinguish between small and medium scale enterprises. Kayanula and Quartey [16] reveal that the first attempt to overcome the definition challenge was by the Bolton Committee in 1971. The Bolton Committee used different criteria (number of employees, assets and turnover) to classify enterprises. Under the manufacturing, construction and mining \& quarrying sub-sectors, the number of employees is used as the indicator for distinguishing small scale enterprise from medium scale and large scale enterprises. Manufacturing, construction and mining \& quarrying firms are considered small if they employ less than 200 workers, 25 workers and 25 workers respectively.

In using a firm's turnover as another distinguishing feature, the Committee points out that a turnover of 50,000 pounds or less is used to classify retailing firms, miscellaneous firms and service firms as small. Additionally, a turnover of 100,000 pounds or less is used to classify motor firms and wholesale firms as small. Thus, whilst a turnover of 50,000 pounds or less is used to classify retailing firms, miscellaneous firms and service firms as small, turnover of 100,000 pounds or less is used to classify motor trades and wholesale trades as small. In the case of road transport firms, the number of vehicles owned by the firm is used as the index for 


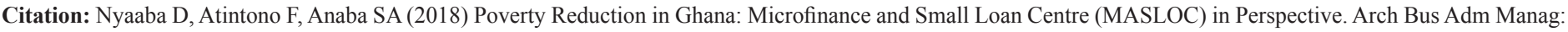
ABAM-119. DOI: 10.29011/ABAM-119. 100019

the classification. A road transport firm is classified as small if it owns five vehicles or less. In terms of ownership of SMEs, the Bolton Committee argues that there is a difficulty distinguishing between ownership and control. Thus, owners of SMEs play dual function (controllers and owners). From the above, the study notes that different criteria are used for classifying firms into different scales. Kayanula and Quartey [16] criticize the Bolton Committee's definitions for using three different upper limits of turnover for the different sectors and two different upper limits of employees. They assert that the definition is complex and do not allow for cross-country comparison. Additionally, the use of monetary units as a basis for comparison is problematic. Using monetary units requires frequent updating to take account of general price changes. Due to the difficulty in defining SMEs especially having a definition that applies to all countries, Storey [17] argue that there is a wide range of measurements for SMEs that vary from country to country. Premising upon the differences that exist among countries' definition of SMEs, the study considers definitions from official sources in Ghana as most relevant. The most commonly used criterion in Ghana is the number of employees [16]. The Ghana Statistical Service (GSS) considers firms with less than 10 employees as small scale and those with more than 10 employees as medium and large-sized enterprises. Thus, the GSS uses the 'employee's criterion' used by the Bolton Committee to define small scale enterprise. Ironically, the GSS in its national accounts considers companies with 9 employees as medium scale enterprises. These inconsistencies in the employees cut off point breed confusion.

\section{Microfinance and Poverty Reduction}

While Hulme [7] indicated that research up to the 1990s tended to focus on how to improve the microfinance industry, rather than on how to prove impact, studies about and questions regarding the impact of microfinance are not new $[7,18,19]$. Some within the microfinance industry argue that the market is an adequate proxy for impact, i.e. client retention and high repayment rates show that poor people are happy with microfinance [20], and that accumulating all the anecdotal stories of the positive impact of microfinance is sufficient. Academic studies though have found mixed impacts, ranging from positive impacts on household income and consumption, to modest or no impact, to negative impacts. Microfinance is universally acknowledged to be one of the most effective and sustainable strategies for poverty reduction by way of bringing financial services to the grassroots communities at close proximity. The fundamental argument for micro-credit and micro-savings, as opined by Stewart, et al. [21] stem from the fact that they allow the poor to invest their money in the future, increase their incomes and lift themselves out of poverty. Changes in income levels of both individuals and households are severally used as a measure of the impact of microfinance on poverty reduction [22]. Microfinance has received extra attention lately, since UN declared 2005 to be the International Year of Microcredit. This correlates well with the Millennium Development Goals, where one of the goals is to decrease by $50 \%$ the proportion of people living in extreme poverty by 2015 [23]. One of the first field experiments about the impact of micro-savings - through a commitment savings account - was undertaken by Dupas and Robinson [24] in rural Kenya, where they found a positive impact on business investment and household expenditure and income. Microfinance has proven to be an effective and powerful tool for poverty reduction. Like many other development tools, however, it has insufficiently penetrated the poorer strata of society. The poorest form the vast majority of those without access to primary health care and basic education; similarly, they are the majority of those without access to microfinance. While there is no question that the poorest can benefit from primary health care and from basic education, it is not as intuitive that they can also benefit from microfinance, or that microfinance is an appropriate tool by which to reach the Millennium goals [25]. This 'microfinancepoverty reduction' debate influenced the Government of Ghana to implement Ghana's Growth and Poverty Reduction Strategy (GPRS) which has microfinance as one of its poverty reduction tools [26]. Literature search revealed that household's income is higher with families who have access to credit as compared to nonborrowers [27] and the poor are more disciplined borrowers and savers, capable of repaying on time and to save [28].

At the core of any poverty reduction programme is the implementation of microfinance scheme. This fact was acknowledged by Otero [4] when he argued that microcredit creates access to productive capital for the poor, which together with human capital, addressed through education and training, and social capital, achieved through local organization building, enables people to move out of poverty. It was added that, by providing material capital to a poor person, his or her sense of dignity is strengthened and this can help to empower the person to participate in the economy and society [4]. But Wright [29] has offered a counter view that income levels cannot be the only measure: increasing income does not per se mean that poverty is reduced, as it depends on what the income is used for. And more recently, the poor are diverse vulnerable households with complex livelihoods [30]. The outcomes used to measure the impact of microfinance on the poor also then have to take into account these changed conceptualisations of poverty and who the poor are.

\section{Profile of Micro-Finance and Small-Loan Centre (MASLOC)}

Since access to sustainable financial services is almost indispensible to any poverty reduction programme, government of Ghana was persuaded to establish the scheme (MASLOC) so as to partly cover the huge credit gap and simultaneously enhance the development of a sound and sustainable micro financial 
system in the country [31]. Microfinance and Small Loans Centre (MASLOC) was established for, first and foremost, prudent and judicious management of Government of Ghana (GoG)/ Development Partners (DP) microfinance funds intended for the scheme and also to facilitate the emergence, development and growth of sustainable and decentralised micro financial services. Its mandate is to undertake the necessary reforms and development measures that would strengthen microfinance operation as an effective and viable strategy for poverty reduction. MASLOC has Board of Directors, management committee at its head office in Accra, regional officers and district officers since its establishment in 2006 to provide micro and small loans to the productive poor of the population [32]. In carrying out such a mandate, MASLOC may promote, educate, enhance and facilitate the operations of non-bank micro-financial institutions and targeted community and users. The fund is expected to make sustainable financial services available to individuals, co-operatives and other groups in grassroots communities in order to help them generate wealth, save and expand their mini-enterprises, leading to urban and rural poverty reduction [32]. The facilities of MASLOC are principally targeted at the marginalised productive poor who fall mostly within the micro, small and medium enterprises sector and focus on women, physically challenged and the youth. The disbursement and recovery of MASLOC loans to clients is done through participating financial institutions. The most common tenure of the loan facilities is 12 months, applicable mainly to commerce, with a one to three months moratorium depending on the nature of the project. The maximum period is up to 24 months which is normally applicable to new projects such as tractor purchase and operation, pineapple cultivation, piggery, as well as institutional lending for the purpose of on-lending or retailing to end-users [32].

\section{Product and Services}

\section{Micro-credit or Group Loans}

Under the micro-credit scheme, the main beneficiaries are groups/cooperative societies, each consisting of a minimum of 5 and a maximum of 25 members. The group shall have common production or operational interest and individuals in the groups must be between 18 and 65 years and of sound mind. An individual within a group can access a minimum of $\mathrm{GH} \notin 100$ to a maximum of GH $\phi 500$. The group solidarity mechanism is applied in this credit scheme. Meaning the whole group is held liable for the repayment of the loan. Thus, until every member within the group has finished paying, the group is considered not to have paid their loan [33].

\section{Small or Individual Loans}

In the case of small or individual loan scheme, an individual can access a minimum loan of $\mathrm{GH} \notin 1,000$ and a maximum of GH $\phi 10,000$. Under this scheme, the loan beneficiary must provide an acceptable security, in addition to a personal guarantor who must be in a position to redeem the loan in case of default [34]. Since October 2007, MASLOC has directly disbursed a total of $\mathrm{GH} \phi 18.3$ million micro credit and small-scale loans to about 30,000 beneficiaries across the country [35].

\section{Objectives of MASLOC}

The aim for setting up the centre is to undertake sound and judicious administration, on fiduciary basis, of government and/ or development partner funds for micro-and small-scale credit programme. In carrying out such a mandate, it may promote, educate, enhance and facilitate the operations of non-bank microfinancial institutions and targeted community and users. The fund is expected to make sustainable financial services available to individuals, co-operatives and other groups in grassroots communities in order to help them generate wealth, save and expand their mini-enterprises, leading to urban and rural poverty reduction. The following are the objectives of MASLOC [32]:

- Coordination, collaboration, complementarily/linkage banking, institutional and capacity building.

- Coordinate operations of associate community based programmes and submit consolidated performance reports to government periodically.

- Enhance the development of a decentralized micro financial system.

- Promote savings and deposit mobilization

- Data and information collection, analysis and dissemination.

- Undertake any other business deemed necessary and appropriate for its cause.

\section{Types of MASLOC's credit}

There are two types of loans run by MASLOC - Microcredit (group) and Small Loans (individual). The scheme (MASLOC) also gives wholesale lending to institutions such as Ghana Cooperative Susu Collectors Association, Ghana Cooperative Credit Union Associations and other Micro Financial Non-Governmental Organizations (MFIs) for on lending to its members. These apart, the project document stipulate that MASLOC shall support special projects targeted at reducing unemployment. These include:

i. Jathropha cultivation for the production of bio-diesel

ii. Youth in Afforestation and Forestation for fighting desertification

iii. Aquaculture

iv. Youth in Agriculture for Block farming

v. Provision of small scale mining/quarrying equipment for Youth in Quarrying and mining programmes 
However, these special programmed have not as yet been implemented.

\section{Eligibility Criteria for MASLOC's Credit}

Principally, the productive poor constitute the main target. However, programmes for women, youth and people with disabilities are prioritized. These are grouped into: microcredit; and small loans [32].

\section{Microcredit}

- A group/ and cooperative concept shall apply in all cases. Therefore, only applicants that have organized themselves into groups or are under cooperative system are eligible.

- The group/cooperative society shall have a minimum of five members to the maximum of twenty-five.

- Preferably group/society shall have common production or operational interest. They should have ongoing business or collectively have the required skill or experience or be prepared to undergo training in credit activity.

- A group/society shall have its leaders and its own internal rules and regulations. The group/society may or may not be registered with Ministries, Departments and Agencies (MDA) or Microfinance Institutions (MFI) or a bank. Such registration shall be an advantage.

- The credit amount may be collectively applied or disbursed on individual basis in accordance with the amount respectively approved for the individual. Only persons with sound minds and aged between eighteen and sixty-five are eligible [32].

- 2.7.2 Small-loans

- These may be accessed on individual or group or cooperative basis. There should be ongoing activity/venture/project.

- There shall be no encumbrance on the existing assets for which the loan is required.

- Sound knowledge of and good experience in the management of the activity/venture/project shall be required.

- The borrower shall be in sound mind and aged between eighteen and sixty-five years. Business /venture may be preferably registered. This does not constitute a requirement but may serve as an advantage.

- A proper title deed to lands for the credit purpose shall be a requirement. Evidence of payment of statutory taxes and levies will be a requirement.

- Possession of a bank account is not a requirement but shall be an advantage.

\section{Procedure for Accessing the Loan}

MASLOC has established offices in all the ten regional capitals of the country with a Head Office in Accra as the coordinating and disbursement centre. A unique application form with security features, with bold inscription "not for sale" written on it, has been printed and given to Field Officers known as Financial Extension Assistants (FEAs) spread across the length and breadth of the country, for distribution to prospective beneficiaries. The information on the form is enough for an individual/group to express request for the funds. The application attracts no application fee and is simple to complete [36].

\section{Factors to be Considered for Approving a Loan}

\section{A. Particulars of applicant}

- Age of individual/proprietor /managing director - whether it falls between 18 and 65 mandatories for MASLOC applicants.

- Residential address - to help determine whether applicant resides in the catchment area of MASLOC regional office.

- Duration of residence at present location of project (town) - to determine the availability of applicant.

- Home town /district - to facilitate tracing when applicant moves from present location.

\section{B. Particulars of business}

- Type of business - whether it falls within MASLOC's limit.

- Activity/project status - whether new or on-going.

- Location/accessibility - whether follow up/monitoring can be done easily.

- Source of production/raw materials and availability.

- Date project was inspected.

C. Particulars of loan

- Amount required.

- Whether loan is new or supplementary.

- $\quad$ Purpose of loan - whether it falls within MASLOC's priority area.

\section{Previous loan}

- Details of any previous loan taken from MASLOC or other institutions - amount granted and name of institution, reasons for arrears, if any,

\section{E. Management, training experience}

- Who will manage the business? - Applicant or hired person. 
- How long manager has been doing the business.

- Relevant entrepreneurial training, skills, experience obtained.

F. Marketing

- Is there ready market for products/services.

- How product will be marketed.

- Competitiveness.

\section{G. Security/collateral}

- Type of security proposed/offered for the loan.

- Type of title to business land and whether it is encumbered.

- MASLOC does not require tangible security like buildings, cars, land etc. Personal guarantors of good financial standing, who can redeem the loan in case of default, are all that is required.

\section{Government Involvement in Microfinance}

To better understand the approach of this study, it is important to point out the paradigms of the finance to the poor. In the 1960 s and 1970s there was an understanding for the need of rural finance, but there was also the recognition of the costs and risks of this type of finance, which made financial institutions reluctant to expand in the rural area. A model of rural finance was developed based in donors and government, becoming the old paradigm of finance to the poor. An example of this paradigm is the initial creditdriven models utilized by the Grameen Bank in Bangladesh in its early stages. The focus under this model is poverty reduction and social change, with non-governmental institutions as the key players. Under this model there is little concern for building an efficient financial market, the objective is just in providing the service. It is common to observe under this paradigm economic policies that are focused on direct government intervention, and not on developing a conducive economic environment that could lead to sustainable financial institutions [37]. The old paradigm supports five characteristic types of government interventions [38]: Subsidized interest rates; (1) Lending requirements; (2) Quotas on banks and financial institutions; (3) Targeted lending by development institutions: (4) Credit guarantees. These five types of intervention have been proven inefficient in the long run. Subsidized interest rates, one of the major reasons for the model's failure, has negative impacts because of the opportunity cost of funds, the lack of sustainability it creates, the grant mentality it brings, and the limit to expansion. The attention to microcredit, created through cheap loans, may draw off funds from projects that can help the poor more, or help a higher portion of the population. The opportunity cost of funds existent when the government engages in these subsidized programs cannot be ignored. In 1959 government instituted loan schemes for rural and agricultural ventures, as these areas were not being served well by commercial banks (such as the Barclays' Bank, Standard Chartered Bank and Ghana Commercial Bank), which focused on the urban areas at the expense of the rural areas. Rural people found the size and bureaucracy of commercial banks, particularly the demand for written documentation, to be unfriendly; they also had difficulty meeting the demand for collateral security. Thus, these banks were regarded as structurally biased against the rural poor. The Bank of Ghana Act (1964) established, among others, the Rural Banking Department. In order to address this state of affairs the Agricultural Credit and Cooperative Bank was established in 1965, and the Agricultural Development Bank was established in 1967. For all banks prior to 1986, the policy was 'provide low interest rate to the rural and agricultural sector and increase proportion of portfolio to agricultural sector'. Furthermore, the Bank of Ghana drew on the experience of Rural and Community Banks (RCBs) in the Philippines and the Netherlands and decided to promote the establishment of such banks in Ghana. This consequently led to the establishment of the first rural bank in 1976.

\section{Typologies of Microfinance}

In spite of its continuous growth, microfinance is diverse in outlook and legal forms. These differences can be seen from the typologies of MFIs. Both Adam [39] and IFAD [40] delimit micro financial typologies to three classifications basing on regulation: (i) formal MFIs regulated by financial authorities of the state (or its appointed agent); (ii) semi-formal MFIs under the control of their registering authorities; and (iii) informal MFIs that are controlled by customary laws and peer pressure. On the other hand, Staschen [41] classifies MFIs into three broad categories depending on the source of funds, viz: (i) NGOs that use other peoples' money (grants and concessionary loans from donors) to fund their social goal-oriented lending business; (ii) community savings and credit groups and village banks that use members' money to grant loans to members exclusively; and, (iii) Government credit institutions that use public money to finance their lending business. In their analysis typologies of microfinance Matin, et al. [30] created a three-by-three matrix, with one axis comprising the financial service components (savings, credit and insurance) and the other axis the providers (informal, formal, and semi-formal providers). Rutherford [42] however based his categorisation on the type of service as well as whether it is owned and managed by the users themselves or other providers. The reality then is a mix of financial services accessed by poor people from a variety of service providers, depending on local knowledge, history, context and need [30].

\section{Microfinance and Access to Credit}

Lan \& Tran's study in Viet Nam identified Microfinance Organization (MFOs) as critical sources of borrowing by clients. 


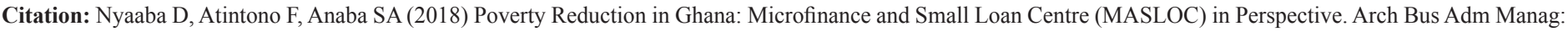
ABAM-119. DOI: 10.29011/ABAM-119. 100019

Lan \& Tran [43] argued in favour of MFOs that, they enhance access to credit through clients borrowing to as high as $43 \%$ of all borrowing. This was greatly attributed to meeting the financial service needs of the poor and clients-centred approach that is being used. Access to microfinance is credited with reaching the poorest, increasing their income, galvanizing them into collective action to resist oppression, with empowering repressed poor people so that they are able to take control of their lives, with enabling families access to better health care, education and nutrition; and with providing a cost-effective, sustainable development model that is applicable not just in developing countries but also among poor communities in the developed world [44]. In addition to these social and development arguments for microfinance, there is an economic case that leads us to expect that improved financial access through microfinance will lead to increase incomes as poor people work themselves out of poverty, and furthermore that targeting women may have the greatest impacts. As Armendariz and Morduch [45] explain, provision of credit in capital-poor, credit-constrained economies should provide relatively high returns on investment compared to capital-rich economies where opportunities are already maximised. Furthermore, by reducing credit constraints and providing financial services in environments where credit is hardest to access, and to groups such as women who are most-commonly excluded from the formal market, the potential for profits is even higher [46].

\section{Empowering the Poor through Microcredit}

Since the 1970s microfinance has come to be seen as an important development policy and a poverty reduction tool for men as well as women and by 2010 over 200 million people were served by thousands of microfinance institutions (MFIs) [47]. Microfinance now includes a suite of financial tools which aim to provide banking services to the 'unbanked' through the provision of small cash loans (micro-credit), the lending of productive assets (micro-leasing), facilities to save (micro-savings), and most recently insurance policies (micro-insurance) and money transfers. These instruments are seen as reducing and mitigating risks and vulnerabilities experienced by poor people [48]. Some even argue $[49,50]$ that microfinance is a key tool to achieve the Millennium Development Goals (MDGs). There is an assumption that extending access to financial services through microfinance will increase wealth and reduce poverty $[51,52]$. Kofi Annan, then the United Nations Secretary General, described micro-credit in 2005 as 'a critical antipoverty tool - a wise investment in human capital. When the poorest, especially women, receive credit, they become economic actors with power. Power to improve not only their own lives but, in a widening circle of impact, the lives of their families, their communities, and their nation' [53]. Empowerment is said to be an important aspect of micro-credit schemes. Kabeer [54] states that empowerment refers to the "process by which those who have been denied the ability to make strategic life choices acquire such ability'; where strategic choices are 'critical for people to live the lives they want such as choice of livelihood'. Therefore micro-credit schemes cannot empower people directly but can help them through training and awareness creation to critique the existing norms, cultures and values which place them at a disadvantage position, and to help them have greater control over resources and their lives. Oakley [55] identifies five key uses of the term empowerment in development studies, from which empowerment through economic improvement and empowerment of the individual are examples. Empowerment through economic improvement is an approach which has been extensively used with poor people. Based on the assumption that, poor people's relative powerlessness is primarily a function of their poverty, therefore interventions such as microfinance and small business activities, targeted at poor people, they will become agents of change in their community. Microcredit creates access to productive capital for the poor, which together with human capital, addressed through education and training, and social capital, achieved through local organization building, enables people to move out of poverty. By providing material capital to a poor person, his or her sense of dignity is strengthened and this can help to empower the person to participate in the economy and society [4]. The aim of microfinance is not just about providing capital to the poor to combat poverty on individual level; it also has a role at an institutional level. It seeks to create institutions that deliver financial services to the poor, who are continuously ignored by the formal banking sector [4].

\section{Challenges Facing the Microfinance Sector}

The microfinance system can be separated into three distinct but integrated levels of activity: micro, meso and macro. The micro level involves both microfinance clients and microfinance service providers. From the borrowers' perspective, challenges often relate to their limited financial sophistication, which can increase their vulnerability to predatory lending practices. From the lenders' perspective, a lack of sustainable funds and limited managerial experience present operational challenges. The meso level includes "support services and infrastructure" (e.g., microfinance associations, credit bureaus, auditors, etc.). Limited capacity, including an inadequate supply of technical service and education providers, presents a challenge at the meso level. The macro level is comprised of central banks, ministries of finance and other national government entities. At this level, systemic failure or a contagious collapse of MFIs, exposed to the same underlying risks is a key challenge for policy makers [56]. At the borrowers' level, Kazmin [57] argued that the small amount that is being disbursed by the microfinance institutions has led to the practice of multiple borrowing. The high interest rates and the use of coercive collection tactics forced some borrowers to commit suicides. This is also the period when a lot of microloan repayment crises were reported in Morocco, Bosnia, Nicaragua and Pakistan [57]. Morduch [58], shifted the debate to the challenges of sustaining 
the microfinance sector as a result of increasing competition and the likelihood of over indebtedness on the part of borrowers. Lan and Tran [43], aptly illustrated evidence of deficit in capacity of the microfinance organizations (MFOs) which affect their ability to access sufficient funding for their operations.

\section{Research Approach}

\section{Research Design}

A case study approach was used as the research strategy by the researcher. The researcher employed the representative single case study [59], primarily designed to elicit information from a cross-section of local stakeholders (especially beneficiaries and management) of MASLOC in the Tamale Metropolis. This has afforded the researcher the opportunity to study and understand how MASLOC has influenced access of local population to micro-credit in Tamale. The researcher combined conventional ethnographic methods (participation observation, semi-structured interviews and focus discussion) with Participatory Learning Approach (PLA) techniques (wealth ranking and community mapping) to ensure triangulation. This study acknowledged the relevance of the constructionist paradigm based on the view that knowledge is socially constructed. This approach posits that there can be multiple perspectives on a single phenomenon hence truth is relative and that it is dependent on one's perspective [60]. To be able to discover the relations and interactions among the variables in real-life and contemporary settings, the case study approach was appropriate in reflecting upon values, interests, experiences, beliefs and political commitments of local communities [61]. This approach therefore creates a collaborative atmosphere between the researcher and the participants and allows the participants to tell their stories. This confirmed the position of Patton [62] of the involvement, and immersion of the researcher into the discussion of the real world situation. The researcher needs to be present during the process of eliciting the values and perspectives of the subjects and/or objects of investigation. It provided the opportunity to explore multiple sources of gathering data from the sample population.

\section{Rationale behind the Case Study Approach}

The case study approach was employed due to the fact that it provided a basis for an empirical enquiry that allows the researcher to investigate and understand the role of MASLOC in the economic life of its credit beneficiaries. It created the avenue to use multiple sources of evidence, thus improving the quality of data for the study as it allows triangulation [63]. A case study provides an opportunity for intensive analysis of many specific details often overlooked by other methods. This approach rest on the assumption that the case being studied is typical of cases of a certain type so that, through intensive analysis, generalisations may be made that will be applicable to other cases of the same type
[64]. Again, since the researcher has very little control over the phenomena being investigated- SMEs access to microcredit - the case study approach is appropriate for the retrospective assessment of the phenomena. This provides precedence, as well as sources of reference for future cases [65]. Finally, this approach enabled the researcher to learn from practice that has enhanced a better understanding of the underlying concepts of microfinance and Small and Medium Enterprises (SMEs).

\section{Shortcomings of the Case Study Approach}

Just like any other research design, the case study design has both advantages and weaknesses in conducting a qualitative research. These shortcomings, if not well managed, can mar the validity, credibility and reliability of observations made from field data. The chosen design (case study) has no control over extrinsic and intrinsic factors. More so, it does not allow for before-after experimental group comparison. In fact, the case study method is limited by lack of adequate control over rival explanations, therefore weak on internal validity [63]. Case studies often contain a substantial element of narrative. Accordingly, such narratives may be difficult or impossible to summarise into neat scientific formulae, general propositions, and theories [66].

\section{The Concept of Population and Sampling}

Methodologically speaking, the entire set of relevant units of analysis or data is called the population. In other words, population is the entire group or set of cases that a researcher is interested in generalising [63]. In this study the population of interest was all individuals, groups and corporate institutions of MASLOC in the Tamale Metropolis. Sampling on the other hand is the process of selecting a few (sample) from a bigger group (the sampling population) to become the basis for estimating or predicting a fact, situation or outcome regarding the population [64]. Sampling is a research technique through which investigators study a manageable number of people, known as the sample, selected from a larger population or group. A sampling procedure that is accurately carried out enhances the external validity of the results. However, error in sampling may compromise the level of accuracy in conclusion or findings of the research.

\section{Sampling Techniques}

A multi-stage sampling technique was adopted for the study at different stages of sampling [64,67]. Respondents were selected on the basis of probability and non-probability procedures. The Metropolis was divided into four (4) zones and within each zone, respondents were classified into "low", "middle" and "high" income residential areas. The study Metropolis was selected purposively while a zone each was selected from each of the categories of "low", "Middle" and "high" income residential areas through cluster sampling. From the sample frame of beneficiaries of MASLOC's credit facilities, simple random sampling was then 


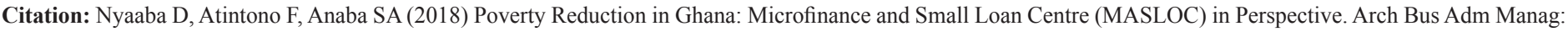
ABAM-119. DOI: 10.29011/ABAM-119. 100019

employed to select the respondents from each category. However, the staff of MASLOC in the Tamale Metropolis, financial institutions which have been disbursing credit and people with specialised knowledge in micro-finance were selected purposively. At least, forty (40) respondents were sampled from each cluster to make a sample size of 120 .

\section{Data Collection Method}

A hallmark of case study research is the use of multiple data sources, a strategy which also enhances data credibility. Unique in comparison to other qualitative approaches, within case study research, investigators can collect and integrate quantitative survey data, which facilitates reaching a holistic understanding of the phenomenon being studied [60]. In this study both quantitative and qualitative methods were employed for data collection. This approach was similar to the view of Flyvbjerg [66] that, an effective combination of qualitative and quantitative methods lead to a valid conclusion. Logical empiricists also take the position that social scientists can attain objective knowledge in the study of the social as well as the natural world [63]. To have a comprehensive assessment of how MASLOC has contributed to accessing microcredit by the SMEs sector, the quantitative and the qualitative methods were combined.

\section{Secondary Data Collection}

The secondary sources of data created the avenue for the understanding and conceptualisation of the concepts of microfinance and small and medium enterprises. To do this, text books, articles, reports, magazines and journals, among other sources were reviewed and analysed. Specifically, secondary data were gathered from the annual reports and records of MASLOC, MASLOC microcredit disbursing financial institutions and the records of groups and associations that have benefited from the credit scheme.

\section{Primary Data Collection}

The study basically employed two instruments to carry out the investigation so as to gather the appropriate data. The main primary data collection instruments were observation and interview techniques (structured, semi-structured and unstructured questionnaire) of gathering information. Specifically, participant observation was used in the study to gather information about the procedures to follow in order to access credit.

The second instrument that was employed to collect data was interview. This instrument helped to collect in-depth information about the socio-demographic data, credit sources, type of business activities, average time for loan application (that is, from application to actual disbursement), loan recovery procedure, the residential and income status of beneficiaries and the location of business activities. However, unstructured interview was employed to gather information from the staff of MASLOC, Microfinance institutions that disburse the loan and NBSSI in the study area. Focus discussion with individuals and/or groups of beneficiaries was used to confirm or correct information that was gathered through structured interviews and observation. Also, the semistructured interview was used to seek specialised information from key informants about sustainability of the scheme.

\section{Analytical Tools}

To systematically search for meaning from the data [68], the researchers employed both descriptive and inferential statistics in analysing both the secondary and primary data. To assess access of economically active group to MASLOC's micro-credit of Tamale Metropolis, descriptive statistics will be employed to organise and analyse the qualitative data. The researcher will make use of the Statistical Package for Social Scientist (SPSS) software for analysis to cross-tabulate education and access to credit, residential status and access to credit and type of business and access to credit. The descriptive analysis will also cover socio-economic and demographic characteristics of the respondents, capacity of beneficiaries, profit margin as well as income, income and gender.

\section{Results and Discussion}

\section{Socio-Demographic Characteristics of Clients}

\section{- Marital Status of Respondents}

Out of a total number of 120 people interviewed, majority were between the age group of 18-38. The analysis revealed that (70 of the respondents) $58.3 \%$ were within the above age group. The 39-59 age group constitutes 30\% while the 60-80 age group represents $11.7 \%$. On the issue of marital status, 94 clients, representing $78.3 \%$ were married. On the other hand, $21.7 \%$ were either single, divorced, separated or widowed (Table 1). This implies that, the clients are likely to have a higher propensity of using a MASLOC credit facility for other household responsibilities than doing business.

\begin{tabular}{|c|c|c|}
\hline Marital Status & Number & Percentage (\%) \\
\hline Single & 16 & 13.3 \\
\hline Married & 94 & 78.3 \\
\hline Divorced & 4 & 3.3 \\
\hline Separated & 2 & 1.7 \\
\hline Widowed & 4 & 3.3 \\
\hline Total & 120 & 100 \\
\hline \multicolumn{2}{|c|}{ Source: Field Survey, April, 2013 } \\
\hline
\end{tabular}

Table 1: Marital Status of Sampled Clients of MASLOC.

\section{Educational Level}

Although the level of education is not one of the criteria for the 


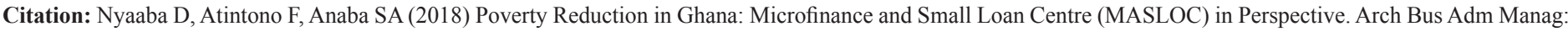
ABAM-119. DOI: 10.29011/ABAM-119. 100019

disbursement of MASLOC loan, there is no ambiguity about the role of education in the utilization of any credit facility by the beneficiary. For this reason, the educational attainment of the beneficiaries of MASLOC credit was analyzed to establish a positive relationship or otherwise of MASLOC clients in the study area (Table 2).

\begin{tabular}{|c|c|c|}
\hline Educational Level & Number & Percentage (\%) \\
\hline Nill & 70 & 59.2 \\
\hline Primary & 12 & 10 \\
\hline JHS/Middle & 18 & 15 \\
\hline SHS/SSS & 18 & 15 \\
\hline Vocational School & 0 & 0 \\
\hline Tertiary & 1 & 0.8 \\
\hline Total Source: Field Survey, April 2013 \\
\hline \multicolumn{2}{|c}{} \\
\hline
\end{tabular}

Table 2: Educational Level of Respondents.

From Table 4.2, 15\% of the respondents had either completed a junior high school or a senior high school. But those who ended at the primary school level or completed a tertiary school were $10 \%$ and $0.8 \%$ respectively. However, as much as $59.2 \%$ of the beneficiaries had never attended school. It is more likely that the absence or low educational level of the respondents will have negative repercussion on their businesses. For example, simple book keeping and general management of the business that involve basic education will not be done properly.

\section{Ethnicity}

The study area is a multi-ethnic in nature. As revealed by (Figure 1), about 90 of the respondents, representing $75 \%$ were from the Dagomba ethnic group. The second largest ethnic group in the study area was the Frafra, comprising of $30 \%$. The other ethnic groups, including the Kasena, Mamprusi and Moshi were $12 \%$ each while the Hausa, Kokomba, Ewe and Bimoba constitute $6 \%$ each.

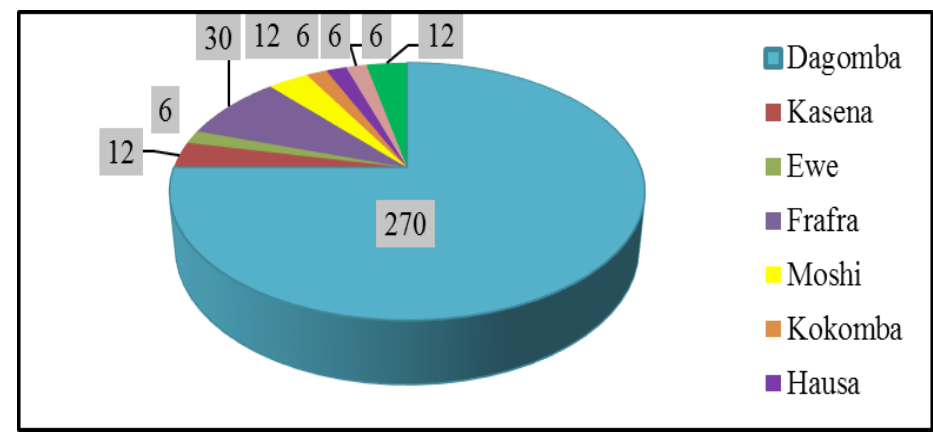

Source: Field Survey, April 2013

Figure 1: Ethnic Composition of the Study Area.

\section{Clients Information about MASLOC}

In the business environment, information is treated as a resource. To offer competitive services and remain innovative, business operators need to obtain information about market for their input and output, and more importantly, the sources of capital. The study therefore assessed whether there adequate information on the activities of MASLOC and where this was obtained from. There was $100 \%$ awareness of the activities of MASLOC in the study area despite the fact that the respondents were skeptical about its operation. The commonest source of information about MASLOC is informally generated which come with distortion.

Within the context of sources of information, as many as $88.3 \%$ of the sampled population got to hear about MASLOC from their friends. Although MASLOC is supposed to be non-partisan in its operation, $5 \%$ of the respondents obtained information on the activities of MASLOC from the various political parties, while $6.7 \%$ heard about MASLOC on the radio. The $0 \%$ recorded for the newspaper source of information confirms the $59.2 \%$ of illiteracy among the sampled population (Table 3 ).

\begin{tabular}{|c|c|c|}
\hline Source & Number & Percentage \\
\hline Friend & 106 & 88.3 \\
\hline Radio & 8 & 6.7 \\
\hline Newspaper & 0 & 0 \\
\hline MIDA/Party & 6 & 5 \\
\hline Total & 120 & 100 \\
\hline \multicolumn{2}{|c|}{ Source: Field Survey, April 2013 } \\
\hline
\end{tabular}

Table 3: Sources of Information about MASLOC.

\section{Clients' Economic Activities}

Tamale Metropolitan area, which is the research area, is a cosmopolitan in nature and inhabitants are engaged in varied business to make a living. The respondents are engaged in myriad of economic activities including food crop production, agroprocessing, micro-enterprise and agro-marketing.

As indicated in (Table 4), 54 of the client respondents, representing $45 \%$ were engaged in agro-processing especially, in Shea butter and groundnut extraction and rice processing (rice par boiling). Those employed in the micro-enterprise sector accounted for $33.3 \%$ of the micro-enterprise category of economic activities included petty sales, sales of cooking utensils and other household goods and clothing. Food crop production and livestock rearing recorded the least patronage of $5 \%$ and $1.7 \%$ respectively.

\begin{tabular}{|c|c|c|}
\hline Type of Economic Activity & Number & Percentage (\%) \\
\hline Food Crop Production & 6 & 5 \\
\hline Agro-processing & 54 & 45 \\
\hline Livestock & 2 & 1.7 \\
\hline
\end{tabular}


Citation: Nyaaba D, Atintono F, Anaba SA (2018) Poverty Reduction in Ghana: Microfinance and Small Loan Centre (MASLOC) in Perspective. Arch Bus Adm Manag: ABAM-119. DOI: 10.29011/ABAM-119. 100019

\begin{tabular}{|c|c|c|}
\hline Micro-Enterprise & 40 & 33.3 \\
\hline Agro-Marketing & 18 & 15 \\
\hline Total & 120 & 100 \\
\hline \multicolumn{2}{|c|}{ Source: Field Survey, April 2013 } \\
\hline
\end{tabular}

Table 4: Major Economic Activities of Respondents.

\section{Sources of Start-up Business Capital}

The study has revealed that majority of the beneficiaries of MASLOC credit facility normally start business on small scales. People start businesses from their little savings from other menial jobs they had been doing or had ever engaged in. All the respondents started their businesses with less than One Thousand Ghana Cedis (GH $\varnothing 1,000)$. Fifty-Six (56) of them, representing $46.7 \%$ benefited from MASLOC credit to start their businesses. Also, $20 \%$ of the respondents funded their micro enterprises from multiple sources. However, about $16.7 \%$ of the married respondents identified spousal support as the source of start-up capital. (Figure 2) has shown that only $5 \%$ of the respondents started their businesses through self-financing while 3\% funded their businesses from other sources. This confirms Matin, et al. [30] conclusion that access to financial services especially, by the poor, is characterized by mixed financial services.

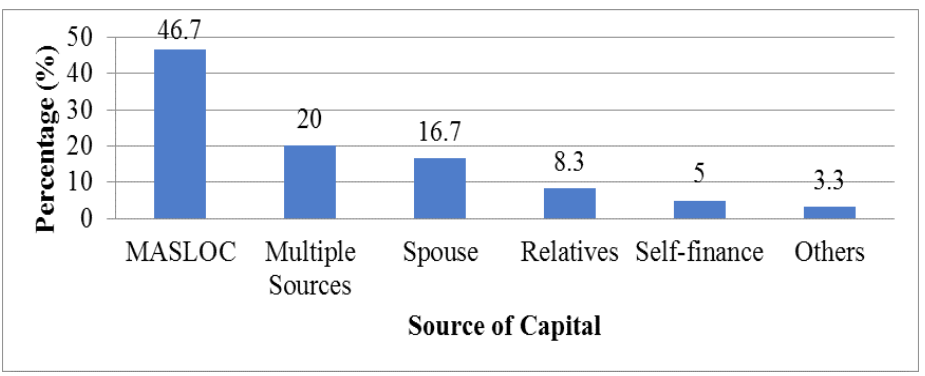

Source: Field Survey, April 2013

Figure 2: Sources of Capital for Small Scale Businesses.
Staschen's classification of microfinance institutions, which was based on source of funding, sources of startup capital for small scale businesses in the study area depend greatly on government instituted micro credit - MASLOC (i.e. government credit institutions). Of the 56 respondents who sourced capital from MASLOC, about $70 \%$ of them confirmed that they have created some form casual or informal employment opportunities for others. Apart from sourcing startup capital from relatives (about $8.3 \%$ ), some family members of owners of small scale businesses also offer non-salary services. One of the determining factors of sustainable operation of small scale businesses is good financial mobilization and management. Although the operation of a bank account is not a substitute for saving, the study established that $83.3 \%$ of the respondents have operated and/or are operating a bank account. The ability to have accounts for business so that savings can always be done and proceeds use to further plan and manage the business for its expansion. About $147 \%$ of those interviewed acknowledged that, their ability to save part of their profit is being affected by payment of school fees and household expenditures.

\section{Economic Activity and Access to MASLOC Credit}

To be able ascertain the incremental benefits of MASLOC credit facility, the study investigated how the establishment of MASLOC has enhanced accessibility to small scale loans by the respondents. To be able to assess the category of economic activities that have more access to MASLOC credit facilities, major economic activities of the respondents was cross-tabulated with the sources of start-up capital for micro-enterprises. Just like what was identified by Lan \& Tran [43] in Viet Nam that Micro Finance Organizations (MFOs) are appropriate sources of funding micro-enterprises for meeting the financial service needs of the poor, the current study also revealed that $46.7 \%$ of all the categories of economic activities accessed credit from MASLOC (Table 5). Some of the respondents revealed that despite the cumbersome procedures involved in the acquisition of MASLOC credit they were able to access their fund. 
Citation: Nyaaba D, Atintono F, Anaba SA (2018) Poverty Reduction in Ghana: Microfinance and Small Loan Centre (MASLOC) in Perspective. Arch Bus Adm Manag: ABAM-119. DOI: 10.29011/ABAM-119. 100019

\begin{tabular}{|c|c|c|c|c|c|c|c|c|c|}
\hline \multirow{12}{*}{ 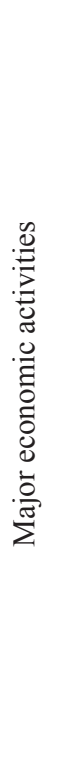 } & \multicolumn{9}{|c|}{ Sources of capital } \\
\hline & Activity & Percent & $\begin{array}{l}\text { Self- } \\
\text { finance }\end{array}$ & MASLOC & Spouse & Relatives & Others & $\begin{array}{c}\text { Mixed } \\
\text { sources }\end{array}$ & Total \\
\hline & \multirow{2}{*}{ Food Crop Production } & Count & 0 & 6 & 0 & 0 & 0 & 0 & 6 \\
\hline & & $\%$ of Total & 0 & 5 & 0 & 0 & 0 & 0 & 5 \\
\hline & \multirow{2}{*}{ Agro-processing } & Count & 4 & 50 & 0 & 0 & 0 & 0 & 54 \\
\hline & & $\%$ of Total & 3.3 & 41.7 & 0 & 0 & 0 & 0 & 45 \\
\hline & \multirow{2}{*}{ Livestock } & Count & 2 & 0 & 0 & 0 & 0 & 0 & 2 \\
\hline & & $\%$ of Total & 1.7 & 0 & 0 & 0 & 0 & 0 & 1.7 \\
\hline & \multirow{2}{*}{ Micro-enterprise } & Count & 0 & 0 & 20 & 10 & 4 & 6 & 40 \\
\hline & & $\%$ of Total & 0 & 0 & 16.7 & 8.3 & 3.3 & 5 & 33.3 \\
\hline & \multirow{2}{*}{ Agro-marketing } & Count & 0 & 0 & 0 & 0 & 0 & 18 & 18 \\
\hline & & $\%$ of Total & 0 & 0 & 0 & 0 & 0 & 15 & 15 \\
\hline & \multirow{2}{*}{ Total } & Count & 6 & 56 & 20 & 10 & 4 & 24 & 120 \\
\hline & & $\%$ of Total & 5 & 46.7 & 16.7 & 8.3 & 3.3 & 20 & 100 \\
\hline \multicolumn{10}{|c|}{ Source: Field Survey, April 2013} \\
\hline
\end{tabular}

Table 5: Relationship between Source of Funding and Economic Activity.

The case for the relationship between sources of startup capital and the category of economic activity indicates that self-financing (5\%) is not a common means of funding microenterprise activities in the study area and agro-processing is the major recipient of this source of funding. Micro-enterprise businesses represent $16.7 \%$ of all economic activities and those engaged in this livelihood activity obtained capital from spouses. However, about $20 \%$ of the respondents took their capital from multiple sources of borrowing and 15\% (18 respondents) of them are engaged in agro-marketing. This confirms an earlier study by Kazmin [57] who also added that this is attributable to the small amount that is being disbursed by the microfinance institutions.

\section{Criteria for Selection of Clients}

In the selection of clients for loan, MASLOC first meets with the individuals or groups and the general public to explain to them what it does. Those who are satisfied with their explanations of modalities of operation will latter submit their application letters. The letters will then be analyzed based on certain qualities, for example, the viability and creditworthiness of businesses and individual's consideration are giving for local realities just to make sure that many people are assisted with loans. Generally, there are five (5) basic factors that are considered in selecting the clients of MASLOC. These include particulars of applicant, particulars of business, particulars of loan, previous loan and management, training and experience. According to the manager of Tamale Metropolitan Area of MASLOC, even though groups are targeted in the disbursement of micro-credit (who are largely women), the loan is shared among the group members.

\section{MASLOC Loan and Disbursement}

Multiple sources of borrowing and the ability of using microcredit to fight poverty is not only explained by ease of access but also the size of credit facility being accessed. The study revealed that the amount of loan disbursed to client is inadequate. About $95 \%$ of the beneficiaries of the scheme received MASLOC loan ranging from $\mathrm{GH} \notin 100$ to $\mathrm{GH} \notin 300$. This condition of small amount of credit to the beneficiaries of the scheme could be explained the demand for collateral security as a criterion for disbursement. The goal of MASLOC which was established in 2007 in the Tamale Metropolis seeks to alleviate poverty in the area through giving loans to micro-enterprises or businesses, individuals and other lenders. After certifying the selection criteria, the amount to be disbursed is then determined. Different ranges of micro-credits are given to new groups and old ones as well as individuals. Most of our women respondents belong to the groups. For the new groups, clients are given between $\mathrm{GH} \varnothing 100-\mathrm{GH} \varnothing 500$, the old or repeat groups receive between $\mathrm{GH} \varnothing 100$ to $\mathrm{GH} \phi 1,000$ and increases by a flat amount of $\mathrm{GH} \notin 500$. The individual are the ones that receive large amount an individual client receives between $\mathrm{GH} \varnothing 1000$ and 
Citation: Nyaaba D, Atintono F, Anaba SA (2018) Poverty Reduction in Ghana: Microfinance and Small Loan Centre (MASLOC) in Perspective. Arch Bus Adm Manag: ABAM-119. DOI: 10.29011/ABAM-119. 100019

GH $\varnothing 10,000$. Out of 120 respondents about 56, representing $46.7 \%$ sourced capital from MASLOC. The study analyzed the views of the clients of MASLOC on the size of credit that was received (Table 5) (Figure 3).

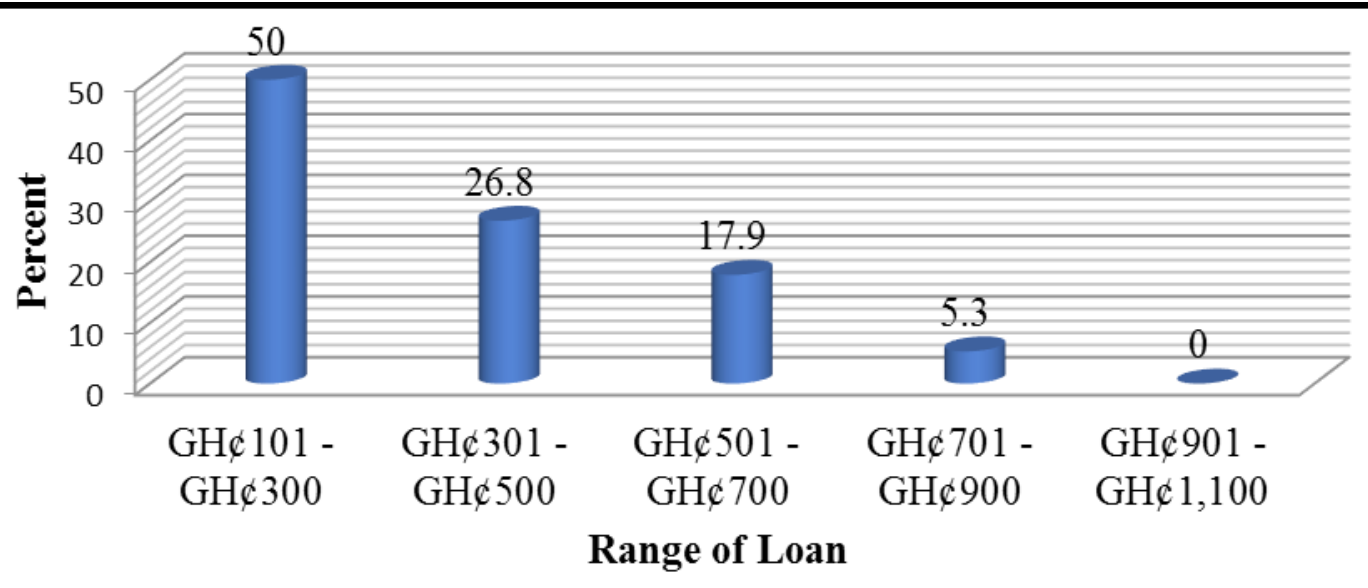

Source: Field Survey, April 2013

Figure 3: Size of Credit Received by Clients.

Majority of the beneficiaries of MASLOC credit received between GH $\varnothing 101$ and GH $\varnothing$ 300. Those who received the lowest range of the scheme's credit constitute $50 \%$. No group or individual client of MASLOC ever received a loan between GH $\not 901$ and GH $\phi 1,100$. However, about $17.9 \%$ and $5.3 \%$ of the clients received $\mathrm{GH} \phi 301-\mathrm{GH} \phi 500$ and $\mathrm{GH} \phi 501-\mathrm{GH} \phi 700$ respectively. The implication is that, the penetration of MASLOC credit may not have significant impact on profitability and income poverty of the respondents.

\section{Disbursements and Repayments Time limits}

There is no specifics time within which a client will receive loan offer application. Also clients immediately start repayments after receiving loans. The belief that, if so much time is allowed after granting of loan, the interest on the loan will also increase which is against the objective of MASLOC. Clients are expected to repay loans granted them after six (6) months. Failure to repay within the stipulated time amounts to action taken against the client by MASLOC, the collateral pledged will be seized or any other appropriate properties. Defaulters can also be dragged to court for non-payment. Group Guarantee Collateral can also be seized in the event of default in payment.

\section{The Impact of MASLOC Loan on Businesses}

The businesses and incomes of 82 respondents, representing $68.3 \%$ acknowledged that there has been an increase in their income after accessing MASLOC credit. Of the 82 beneficiaries of MASLOC credit facility, $71.9 \%$ (59 respondents) of them realized an increase in income from about $\mathrm{GH} \phi 10$ to $\mathrm{GH} \phi 200$.
The remaining beneficiaries $(28.1 \%)$ got an increase in their income level from GH\& 250 to GHф 600. However, after taking the loans, the number of those whose income has grown more than GH $\varnothing 200$ increased about $50.9 \%$. This means they now have more money and their businesses grown. This implies that the clients of MASLOC credit facility will be in the position to take up more of the household financial responsibilities (Table 6).

\begin{tabular}{|c|c|c|c|c|}
\hline \multirow{2}{*}{ Income Status } & \multicolumn{2}{|c|}{ Number (N) } & \multicolumn{2}{c|}{ \% of Respondent } \\
\cline { 2 - 6 } & Before & After & Before & After \\
\hline Increase & 11 & 82 & 9.1 & 68.3 \\
\hline Decrease & 12 & 5 & 10 & 4.2 \\
\hline Constant & 2 & 8 & 1.7 & 6.7 \\
\hline Sub-Total & 25 & 95 & 20.8 & 79.2 \\
\hline Grand Total & \multicolumn{5}{|c}{$\mathbf{1 0 0}$} \\
\hline \multicolumn{7}{|c}{ Source: Field Survey, April 2013 } \\
\hline
\end{tabular}

Table 6: Income of Before and After Benefiting from MASLOC Credit.

The study further indicated that $10 \%$ of the beneficiaries witness a decline in their income before MASLOC loan and 4.2\% are still experiencing a decrease after taking the loan. However, $1.7 \%$ and $6.7 \%$ acknowledged a constant flow of income before and after taking the loan respectively. What can be deduced from the above is that, the clients of MASLOC need some skill training in the management and efficient utilization of their financial resources. 


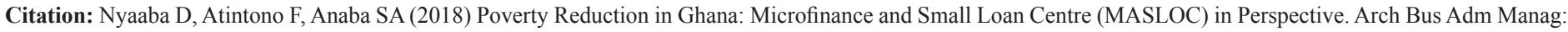
ABAM-119. DOI: 10.29011/ABAM-119. 100019

\section{Challenges in the Operation of MASLOC}

Knowledge about challenges of management of MASLOC precedes efforts of stakeholders in addressing them. There seem to be some kind of symbiotic relationship between efficient management of the scheme and its sustainability. From the perspective of MASLOC, any issue that hinders the attainment of the desired goal of making micro credit accessible to the poor is a problem worth investigation. Management of MASLOC in the study area admittedly reported that majority of the beneficiaries lacked formal education, accordingly, they do not have the experience to understand and manage even low level business activities. MASLOC described this group of clients as being "financial and business illiterate". However, these categories of clients apply for loan that is higher and beyond their financial and managerial capacity. The direct consequence of the above situation is low loan recovery rate. An official of MASLOC in the study area asserted that, the operation of MASLOC is being challenged by political interference. He added that "most people who come for loans on the basis of political patronage tend to think that the loans are handouts to party supporters and therefore do not need to payback. This has led to a high default rate of more than $80 \%$. This undoubtedly affects the operational and financial sustainability as well as drifting the mission of MASLOC. The push for MASLOC to be sustainable in the short and long terms is challenged in the sense that it has to balance the pursuit of social impact, while generating enough profit (although the scheme is principally aim at profit) to self-sustain the cost of operation. The inadequacy of the amount of fund available for disbursement vis- à -vis the number of loan applications is a serious concern for management of the scheme. The ever-increasing number of potential beneficiaries is putting more than bearable pressure on the management of the scheme. The good industrial practice in micro- credit scheme of making loans available to clients for at least three cycles is being defeated in the case of MASLOC as those could not access the scheme's loan in the first round are given the chance in the second round.

\section{Challenges face by Clients of MASLOC}

Sustainable operation of MASLOC is equally linked to addressing the challenges that are faced by the beneficiaries of the scheme's loan. Some of these challenges go beyond the financial and business environment as extended family responsibilities weigh on the efficient utilization of the loan as well as the profit generated. It has been revealed that the top two challenges of the beneficiaries of MASLOC were size of the credit being offered and the difficult documentation processes (Table 7).

\begin{tabular}{|c|c|c|}
\hline Major Challenge & Number (N) & $\begin{array}{c}\text { Percentage } \\
(\%)\end{array}$ \\
\hline $\begin{array}{c}\text { Cumbersome Application } \\
\text { Procedure }\end{array}$ & 24 & 20 \\
\hline
\end{tabular}

\begin{tabular}{|c|c|c|}
\hline Small Amount of Credit & 76 & 63.3 \\
\hline High Interest Rate & 3 & 2.5 \\
\hline $\begin{array}{c}\text { Use of Coercive Collection } \\
\text { Tactics }\end{array}$ & 6 & 5 \\
\hline Lack of Market & 10 & 9.2 \\
\hline Total & 120 & 100 \\
\hline
\end{tabular}

Table 7. Perceived Challenges of MASLOC Clients.

Majority of the clients (63.3\%) are of the view that though they receive micro-credit from MASLOC, the amount disbursed is small an amount to cause a significant change in their business fortunes. Also, 24 of the respondents, representing 20\%, identified difficulties in accessing the loan particularly in the areas of particulars of business and particulars of loan. This difficulty is attributable to lack of proper decentralization in the finalization of loan request as the head office in Accra is involved in the process of granting loans. About $9.2 \%$ of those who are finally given the loan opined that they face the challenge of lack of market for their goods and services. Although the clients of MASLOC acknowledged the need for repayment of credit advanced to them yet, $5 \%$ said that the coercive collection tactics employed by the scheme is not only a challenge to their enterprises but also tarnishes their reputation.

\section{Conclusion}

\section{Findings of the Study}

Un-official Means of Publicity: The study revealed that information about the activities and operations of MASLOC are everywhere. This was not however made available through the official means of educating the public but rather friends. This distorts information that is needed by clients and potential clients to put in accurate application. In reality, management of the scheme felt that they already have a backlog of application therefore engaging in advertisement will increase the number of applications.

Multiple Sources of Borrowing: Just like most informal activity in the micro enterprise sector, the current study has found that an appreciable number of the sampled population borrow from different sources. Since the conditions of access, interest rate and repayment are not aligned, borrowing to start a micro enterprise in the Metropolis exerts great pressure on the recipients when paying for several loans at the same time.

Economic Activity and Sources of Funding: It also been found that among all the economic activities that are being engaged in, agro-processing (45\%) and micro enterprising (33.3\%) had more patronage than the rest. The choice of these activities was 
supported by the availability of raw material for processing and relatively ready acceptance of goods and services of the micro enterprise sector. Whereas agro-processing was mainly funded from MASLOC (41.7\%) and self-financing (3.3\%), the sources of capital for the micro enterprise activities were obtained from spouses $(16.7 \%)$, relatives $(8.3 \%)$, multiple sources $(5 \%)$ and others $(3.3 \%)$.

Credit Accessibility and Income: Although in small amount, the study has established that the establishment of MASLOC in the Tamale Metropolitan area have made micro credit accessible to about $46.7 \%$ ( 56 beneficiaries) of the respondents. Out of this number, as many as 53 beneficiaries $(95 \%)$ received as little as $\mathrm{GH} \notin 100$ to GH $\notin 300$ from the scheme. Considering the number of application and those who have access to MASLOC loan, accessibility is on the low side. However, $68.3 \%$ of those who benefited from the credit facility acknowledged an increase in their economic return.

Size of Credit: The purpose of the MASLOC scheme is principally not to make profit but to provide access to microfinance to Ghanaians who otherwise may not have this opportunity. The study had revealed that economic activities such as agro-processing and micro enterprising have received funding from the scheme. However, the amount of credit disbursed to beneficiaries is small compared to the financial requirements of the group or individual clients. This had made some of the respondents to resort to multiple sources of funding their business activities.

Capacity of Utilization: The ability to create more value from a credit facility is correlated to the effective and efficient utilization by the borrower. It has been found that some of the loan applicants do not have the requisite capacity and hence do not qualify to be given the credit. Using particulars of business criterion, which focus on type of business, project status, location and source of raw materials and their availability, many of the micro enterprises have low capacity. In spite of low capacity to utilize the loan, political pressure and interference is used for such people and groups to be granted the credit.

Recommendation: Using micro credit from MASLOC as a catalyst for reducing poverty and enhancing livelihood of the beneficiaries, it has been recommended that the scheme, policy makers and other agents of change should redirect their resources and efforts towards increment in loan portfolio, encouraging micro-savings, monitoring performance, training of beneficiaries and delinking MASLOC from politics. The recommendations should help in refocusing micro finance policy, regulatory enforcement and review of the micro credit and small scale loan sectors.

Increase Loan Portfolio: It is true that MASLOC aim at making micro credit accessible to the poor, poverty can effective be reduced if loans portfolios are diversified over a large number of clients with different risk profiles. Then, if one risk factor turns out negative, not all the portfolio will be affected. Those who are engaged in the agro-processing sub-sector will be less active in the lean season when their inputs from farmers become scarce and hence difficult to repay their loan. However, those in the micro enterprise sector have good sales in the dry season. This means that the nature of business should be used to vary the time of granting loan and the category of beneficiaries at a time. Also, loan concentration risk should be avoided, by desisting from 'connected lending' to clients who are directly or indirectly connected

\section{Micro Savings}

MASLOC has concentrated its resources and attention on micro credit to the neglect of micro savings. Although the scheme does not operate like a financial institution, the banks through clients received credit should be used to encourage the culture of micro savings. This deposit services should be linked to credit, either as a compulsory condition of having a loan, or part of a combined intervention in which a group saves, and then members are allowed to borrow from their shared savings resource. This will function both as a protection to ameliorated the impact of shocks and promotion to build an asset base.

\section{Monitoring Performance}

Better business practices are not limited to credit management and ownership of loanable funds. The management of MASLOC should go beyond the administration and move into assessing the performance of clients. This will call for monitoring and continual supervision of the social and financial performance of micro and small scale enterprises that have benefited from the scheme. High performers should be rewarded with more credit while poor performers are denied second round of credit.

\section{Training of Beneficiaries}

Even though training forms part of MASLOC scheme as a criterion for access, political interference and pressure have undermined this role. Therefore, clients were granted loan without recourse to the issue of capacity. To able o improve upon the capacity and skills of the clients for effective utilization of loans, MASLOC need to complement its activities of credit management with non-financial services such as training.

\section{Delinking the Scheme from Politics}

It is not news that MASLOC is government establishment and as such there is too political interference in staff recruitment and disbursement of loans. Political interference and patronage become intensified when one regime is changed which culminate into change in management and category of clients. This does not allow for following up on programmes and retention of quality staff. Many of the beneficiaries consider the loans as handout 
Citation: Nyaaba D, Atintono F, Anaba SA (2018) Poverty Reduction in Ghana: Microfinance and Small Loan Centre (MASLOC) in Perspective. Arch Bus Adm Manag: ABAM-119. DOI: 10.29011/ABAM-119. 100019

from a political party which affect loan recovery rates and reduce the ability of the scheme to fight poverty. The scheme should therefore be delinked from political domineering and given more autonomy.

\section{References}

1. Annim SK, Awusabo-Asare K, Asasre-Mintah D (2008) Spatial and Economic Dimensions of Clients of Microfinance Institutions in Ghana. Journal of Geography and Regional Planning 1: 86-95.

2. Zaman H (2004) Micro-Finance in Bangladesh: Growth, achievements and Lessons. In: World Bank (Ed.), Scaling up poverty reduction: Case studies in Microfinance. World Bank, Washington, DC 2004.

3. United Nations General Assembly (2003) Programme of action for the international year of microcredit, 2005. (A/RES/58/221). New York 2003.

4. Otero M (1999) Bringing development back, into microfinance. Journal of Microfinance 1.

5. Bank of Ghana (2007) A Note on microfinance in Ghana 2007.

6. Latifee $\mathrm{HI}$ (2007) The future of microfinance: Visioning the who, what, when, where, why, and how of microfinance expansion over the next 10 years 2007.

7. Hulme D, Mosely P (1996) Finance against poverty. Volume I and II, London: Routledge 1996.

8. Cobbold EA, Akobour-Debrah K, Kommey FK (2008) A Examination of financial reporting standards of SMEs in Ghana. University of Ghana Business School, Legon 2008.

9. Ayuure KA (2006) NPP is there for the poor. The Statesman Newspaper 08-09-2006.

10. United Nations (2008) Microfinance sector assessment-Ghana. United Nations advisors group on inclusive financial sectors 2008.

11. Elahi KQ, Rahman ML (2006) Micro-credit and micro-finance: Functional and conceptual differences. Development in Practice 16: 476483.

12. Brau JC, Woller GM (2004) Microfinance: a comprehensive review of the existing literature. Journal of Entrepreneurial Finance and Business Ventures 9: 1-26.

13. Hossain F (2002) Small loans, big claims. Foreign Policy 12: 79-82.

14. United Nations (2005) Building inclusive financial sectors to achieve the Millennium Development Goals. International Year of Micro-credit. New York 2005.

15. Almeyda G, Branch B (1998) Micro finance in Guatemala: The Case of credit unions. Madison, Wisconsin, USA; World Council of Credit Unions 1998.

16. Kayanula D, Quartey P (2000) The policy environment for promoting small and medium-sized enterprises in Ghana and Malawi", an article published in Finance and Development Research Programme working paper series, IDPM, University of Manchester 2000.

17. Kufuor AA (2008) Employment generation and small medium enterprise (SME) Development-the garment and textile manufacturing industry in Ghana", paper presented at the International Forum on
Sustainable Private Sector Development on growing inclusive markets forum in Halifax, Nova Scotia, Canada, at Dalhousie University's Faculty of Management 2008.

18. Goldberg N (2005) Measuring the impact of microfinance: taking stock of what we know. Washington DC: Grameen Foundation 2005.

19. Rogaly B (1996) Micro-finance evangelism, destitute women, and the hard selling of a new anti-poverty formula. Development in Practice 6: 100-112.

20. Wrenn E (2005) Micro-finance: literature review. Retrieved on 25 June, 2012 from, www.dochas.ie 2005.

21. Stewart R, Van Rooyen C, Dickson K, Majoro M, De Wet T (2010) What is the impact of microfinance on poor people? A systemic review of evidence from Sub-Saharan Africa. Technical Report. London: EPPI-Centre, Social Research Unit, University of London 2010.

22. Makina D Malobola LM (2004) Impact assessment of microfinance programmes, including lessons from Khula Enterprise Finance. Development Southern Africa 21: 799-814.

23. Lindvert M (2006) Sustainable development work and microfinance: A case study of how ECOLOF Ghana is working towards financial sustainability. (Unpublished Master Thesis); Mid Sweden University 2006.

24. Dupas P, Robinson J (2009) Savings constraints and microenterprise development: evidence from a field experiment in Kenya. National Bureau of Economic Research 2009.

25. Morduch J. and Haley B (2002) Analysis of the effects of microfinance on poverty reductuion. NYU Wagner working paper 2002.

26. Ministry of Finance and Economic Planning (2003) General Background on Global Microfinance Trends 2003.

27. Remenyi J, Quinones B (2000) Microfinance and poverty alleviation: Case studies from Asia and the Pacific. New York 79: 253-263.

28. UNICEF (1997) Give us credit. Division of evaluation, policy and planning. New York, UNICEF 1997.

29. Wright GAN. (1999) Examining the impact of microfinance services: Increasing income or reducing poverty? Journal of Small Enterprise Development 10: 38-47.

30. Matin I, Hulme D, Rutherford S (1999) Financial services for the poor and poorest: Deepening our understanding to improve provision ( $\mathrm{Fi}-$ nance and development research programme working paper series no. 9). Manchester: IDPM, University of Manchester 1995.

31. Asiama JP, Osei V (2007) Microfinance in Ghana: an overview. Economic Web institute. Working Paper, Bank of Ghana 2007.

32. Micro-finance and Small Loan Centre [MASLOC] (2008) Annual report; MASLOC, Accra 2008.

33. Fant EK (2010) Fighting poverty with micro-credit: Experiences from Micro-Finance and Small-Loan Center (MASLOC) in Savelugu/Nanton District of Northern Ghana (Unpublished Thesis); Norwegian University of Life Sciences, Norway 2010.

34. Daily Graphic (2009). MASLOC and access to micro credit by the poor 11.

35. Ghanaian Times (2008). Beneficiaries of small scale loans under MASLOC 17: 9 . 
Citation: Nyaaba D, Atintono F, Anaba SA (2018) Poverty Reduction in Ghana: Microfinance and Small Loan Centre (MASLOC) in Perspective. Arch Bus Adm Manag: ABAM-119. DOI: 10.29011/ABAM-119. 100019

36. Micro-finance and Small Loan Centre [MASLOC] (2009) Annual report; MASLOC, Accra 2009

37. Lapenu C (2002) The microfinance revolution: implications for the role of the state. In M. Zeller and R. Meyer (Eds.). The triangle of microfinance: financial sustainability, outreach, and impact. Baltimore: Johns Hopkins University Press 297-320.

38. Nagarajan G, Meyer RL (2005) Rural finance: recent advances and emerging lessons, debates, and opportunities. Reformatted version of Working Paper No. (AEDE-WP-0041-05), Department of Agricultural, Environmental, and Development Economics. Columbus: The Ohio State University 2005.

39. Adams D W (1994) Using contracts to analyse informal finance. In F.J.A. Bouman \& O. Hospes, [eds.], Financial landscapes reconstructed. The fine art of mapping development 11: 1-117.

40. IFAD (2001) Rural finance: From unsustainable projects to sustainable institutions for the poor. Rome: GMS Grafiche 2001.

41. Staschen S (1999) Regulation and supervision of microfinance institutions in South Africa. GTZ, Eschborn-Germany 1999.

42. Rutherford S (1996) A critical typology of financial services for the poor. London: ActionAid and Oxfam 1996.

43. Lan L, Tran N (2005) Towards a viable microfinance sector in Viet Nam: Issues and challenges. Viet Nam, International Labour Organization (ILO) 2005.

44. Wright GAN (2000) Microfinace systems: Designing quality financial services for the Poor, London and New York: Zed Books Ltd 13: 11941195.

45. Armendariz de Aghion B, Morduch J (2010) The economics of microfinance, [2nd ed]. Cambridge, Massachusetts: MIT Press 2010.

46. De Mel S, McKenzie D, Woodruff C (2009) Are women more credit constrained? Experimental evidence on gender and microenterprise returns. Applied Economics 1: 1-32.

47. Maes, J P, Reed LR (2012) State of the Microcredit Summit Campaign report 2012. Washington DC: Microcredit Summit Campaign 2012.

48. Hulme D, Moore K, Barrientos A (2009) Assessing the insurance role of micro savings. DESA Working. New York: Department of Economic and Social Affairs, United Nations Pg. No: 83.

49. Littlefield E, Morduch J, Mesbahuddin SH (2003) Is microfinance an effective strategy to reach the Millennium Development Goals? CGAP Focus Note 2003.

50. Simanowitz A, Brody A (2004) Realising the potential of microfinance. Insight 51: 1-2.

51. Grameen Bank (2009) What is microcredit?. 2009.
52. Khandker S (2005) Microfinance and poverty: evidence using panel data from Bangladesh. The World Bank Economic Review 19: 263286.

53. UNCDF (2005) Building inclusive financial sectors to achieve the Millennium Development Goals: Concept paper. UNCDF 2005.

54. Kabeer N (1999) Resources, agency, and achievements: Reflections on the management of women's empowerment. Development and Change 30: 435-464.

55. Oakley P (2001) Evaluating empowerment: Reviewing the concept and practice. Oxford: INTRAC 2001.

56. Ali A, Kim H, Morse J, Salmaso S, Spann K (2009) Improving microfinance governance: A role for the Asia Foundation 2009.

57. Kazmin A (2010) Microfinance: small loan, big snag. Financial Times 2010.

58. Morduch J (1999) The microfinance promise. Journal of Economic Literature 37:1569-1614.

59. Yin RK (2009) What are the potential single-case designs (Types 1 and 2)? Rationale for single-case designs, case study research: design and methods $4^{\text {th }}$ Edition California: SAGE Publications, Inc. Pg. No: 47-53.

60. Yin RK (2003) Case study research: Design and methods $3^{\text {rd }}$ Edition. Thousand Oaks, California, Sage Publications 2003.

61. Kerlinger FN, Lee HB (2000) Foundations of behaviour research. $4^{\text {th }}$ Edition. London: Wadsworth Thompson Learning 2000.

62. Patton MQ (2002) Qualitative evaluation and research methods $3^{\text {rd }}$ Edition. Thousand Oaks, CA: Sage Publications, Inc 2002.

63. Frankfort-Nachmias C, Nachmias D (1996) Research Methods in the Social Sciences $5^{\text {th }}$ Edition. Oxford University Press, New York 1996.

64. Kumar R (1999) Research Methodology: A Step by Step Guide for Beginners. Australia, Addison Wesley Longman, Australia Ply Limited 1999.

65. Kumekpor TBK (2002) Research Methods and Techniques of Social Research. Sonlife Press and Services, Accra 2002.

66. Flyvbjerg B (2004) Five Misunderstandings about Case-Study Research. In: Seale C, Gobo G, Gubrium JF Silverman D Qualitative Research Practice. London and Thousand Oaks, CA: Sage Pg. No: 420-434.

67. Vandana D, Potter RB (2006) Doing Development Research. London, Sage Publications 2006.

68. Hatch JA (2002) Doing qualitative research in education settings. Albany: Suny Press 2002. 